May 2014

\title{
Privacy, Restriction, and Access: Legal and Ethical Dilemmas
}

Camila Z. Tessler

University of Arizona, msetsrle@email.arizona.edu

Follow this and additional works at: https://scholarworks.sjsu.edu/ischoolsrj

Part of the Archival Science Commons

\section{Recommended Citation}

Tessler, C. Z. (2014). Privacy, restriction, and access: Legal and ethical dilemmas. SLIS Student Research Journal, 4(1). Retrieved from: http://scholarworks.sjsu.edu/slissrj/vol4/iss $1 / 5$

This article is brought to you by the open access Journals at SJSU ScholarWorks. It has been accepted for inclusion in School of Information Student Research Journal by an authorized administrator of SJSU ScholarWorks. For more information, please contact scholarworks@sjsu.edu. 


\title{
Privacy, Restriction, and Access: Legal and Ethical Dilemmas
}

\begin{abstract}
This paper examines the intersection of privacy and access in archival repositories. Archival repositories are well known for containing restricted material, and for protecting the privacy of the donors. This literature review examines the need for restricted material from both legal and ethical standpoints, as well as discussing culturally sensitive materials while determining what archives and libraries can do to protect both themselves and their donors while enhancing accessibility and freedom of information.
\end{abstract}

\section{Keywords}

archives, restriction, privacy, ethics, legal, access

\begin{abstract}
About Author
Camila Tessler graduated from the University of Arizona with a Masters of Arts in Information Resources and Library Science and from Newcastle University with a Masters of Letters in Children's Literature. Her work at the University of Arizona's special collections included the Diane Wakoski collection, and the Richard Summers collection. Her previous academic work has been presented at the Manchester Postgraduate Symposium on Childhood and includes work on Neil Gaiman and his children's work.
\end{abstract}


One of the most crucial and essential elements of archival access practice is the concept of privacy and how that intersects with accessibility. Privacy is the crux of any archive's collection policy, because any archive must take into account the restrictions placed on a collection, either by the creator, the government, or the creator's cultural groups, and how those restrictions may impact collection accession, processing, and accessibility. While many collections do not feature restrictions, collections that do tend to have various reasons for their inclusion, but most of these reasons end up being distilled into one crucial element - privacy. The examination of the literature can be divided into two interrelated but distinct schools of thought. There is an intensely legal argument that discusses the concept of privacy, and a more ethics based argument that discusses the concept of restriction. This literature review goes over the various legal and cultural practices put in place by privacy and examines the intersection of personal privacy and archival access, as it is currently being examined by several academic bodies, which include experts from the archival and information science field as well as the legal field.

The first matter that must be addressed is what is meant by personal privacy. The definition of personal privacy can and does vary based on usage and context. Notably, Valge and Birgit (2007) state that "the concept had not been clearly defined (or cannot be defined) and as a result access varies considerably from state to state" (Valge and Birgit, 2007). Arguably, privacy can change features in a home environment, where work topics may be considered private but religious topics are not, or a work environment, where the opposite is true. In information spaces, which encompass both libraries and archives, privacy continues to change shape, but also from country to country and even within cultural groups. Libraries, for instance, do not consider author and creator privacy when determining collection practices. Rather, library privacy policies are determined with the privacy of the user in mind. Chmara (2009) clearly outlines the responsibility that libraries have in reference to the protection of users. "When patrons use the library, they expect that the library personnel will make every possible effort to protect their privacy", (Chmara, 2009) she clarifies, addressing the fact that without this protection of privacy, "patrons will refrain from selecting certain reading materials, fearing public disclosure" (Chmara, 2009). These policies can and do extend to users of archives and archival materials. However, archives have a further responsibility to not only the users of the material, but the creators of personal, corporate, and government collections to protect their privacy as well. For the purpose of this literature review, unless otherwise specified, the concept of privacy will refer directly to the protection of creators, whether those bodies are individuals, cultural groups, or corporate in nature.

To begin the examination of privacy, it's crucial to look at an overview of the legal definitions. Bryan M. Carson (2007) provides an excellent overview in his book, The Law of Libraries and Archives, which details not only the legal context for libraries and archives and the nature of the laws that they are operating under, but also contextualizes these laws in practical, day-to-day settings. This overview is thorough and complete, and covers topics from the application of the First Amendment to copyright and patent law, and the complexities of these laws in archive settings. To understand how the creator is protected by copyright, Carson explains, "intellectual property protection gives creators the exclusive right to the use of products of their imaginations for a limited time period" (Carson, 2007). However, Carson goes on to explain that under the law, libraries and archives have the right to copy materials that are under copyright for particular patron use - that is to say that when material is given to a library or an archive, that some copyright control originally owned by the creator (the exclusive right to the 
use of products of their imagination) is transferred to the archive. While several legal rules continue to govern the use of these items, in essence, the archive assumes the right to reproduce any material given to them in good faith (Carson, 2007). Further, archives "are not liable for infringements made by their patrons, as long as the workers don't have knowledge that the items are going to be used in an infringing manner" (Carson, 2007). All this amounts to a picture of how materials given to archives can be used by patrons, which is critical in the understanding of creator privacy.

The legal issues are further examined by Sniffin-Marinoff (2007), who begins to examine the ever-increasing privacy laws, which include Family Education Rights and Privacy Act (FERPA) and the Health Insurance Portability and Accountability Act (HIPAA) and how those privacy laws impact archivists and the increasing need to be aware of restriction and restricted materials, suggests that "it would be useful to learn more about the challenges - and there are many - faced by college and university archivists beyond FERPA" (Sniffin-Marinoff, 2007). However, her outline is lacking in depth and in practical, viable suggestions for solutions to the problems faced by guidelines such as FERPA. Tim Pyatt (2008) expands on this idea, however, insisting that "we must have a growing knowledge of the laws and regulations that govern our records" (Pyatt, 2008). Pyatt outlines the situation with FERPA and HIPAA and the use and protection of personal material in archives that can be used legally (such as Social Security Numbers). Pyatt discusses the institutional fear of litigation, the legal ramifications of the release of information in collections and records kept by archives. While he focuses primarily on institutional archives, his analysis can be applied to state, historical, and any archive that may have public access. The analysis goes further to detail the problems with specific kinds of documents, such as email, oral materials, sensitive research material and even scrapbooks, stating that "student organizations may donate scrapbooks with materials that later generations might consider objectionable" (Pyatt, 2008). Pyatt's discussion of HIPAA is expanded by Wiener and Gilliland (2011), who begin by examining the issues that are present in any archive or institution with a health science history. HIPAA, like FERPA, protects confidential information: in this case, health information. But health science libraries and archives, Wiener and Gilliland point out, often hold material that is needed by researchers, but violates HIPAA regulations. "In the past,", they point out, "archivists and special collections librarians have often used rules of thumb, such as 'grandfather' clauses, for controlling access to sensitive material...these thresholds are no longer adequate” (Wiener and Gilliland, 2011) as HIPAA regulations are changing to be more strict. Policy, then, must also change to keep up with the changing regulations.

Pyatt goes on, however, to discuss and suggest ramifications and possible solutions. He recommends the use of legal advice, clear documentation of archives and their legal responsibilities and privacy rights through the use of forms that are presented both to archivists and creators, and formation of clear access policies. These suggestions are echoed throughout archive management texts; Michael Kurtz (2004) recommends that "access policy...outline(s) who may use archival collections, when such collections are open for research, and how researchers can gain access to closed collections." (Kurtz, 2004). Benedict (1989) recommends that at accessioning, privacy and restriction should be taken into account to determine if collections should be transferred if they have restrictions in place, suggesting that "records that will not be available for research use for a significant period need not be transferred to a repository immediately," (Benedict, 1989) and that these restrictions should be well documented in accession documentation. Wiener and Gilliland suggest that "a more practical approach is to 
focus on policies that support the traditional function and goals of collections in medical history" (Wiener and Gilliland, 2011) as closing access while laws are written is impractical and costly for repositories. All of these recommendations are made on the idea that the archive must protect the creators from invasion of privacy, as many collection materials may contain sensitive and private information (some of which the creator may feel comfortable releasing upon his or her death, or upon the death of close relations) but also with the intention of protecting the archive from litigation.

The issue of privacy in archival situations, in this case, has been outlined in these cases as a strictly legal situation. Legally, the archive has a responsibility to both the creator and to the archive itself to protect archival material and archival collections from the potential of lawsuits that hinge on the infringing of privacy by users. In all these scenarios, the user is never at any risk for a lawsuit, because, as clearly stated by Carson, the right (and therefore, the liability) of copying information resides with the archive and not with the user.

However, the idea of legal use of archive material is further complicated in scenarios which involve government accountability. This can include material gathered by government agencies about a third party which the third party may not be willing to share with the general public. Paul Stillitoe (1998) discusses this at length in regards to the legal right to privacy in the United Kingdom, but claims that "to move forward, we must look beyond our own national horizons, and liaise more closely with colleagues facing similar situations thought the world" (Stillitoe, 1998), which suggests that he is more than willing to deal with this situation at an international level. He points out that government recordkeeping and the attitudes that govern the dissemination of information have been changing (something that is reflected in the United States through the use of policy such as HIPAA and FERPA). His paper, however, focuses on the new legislation in the United Kingdom that controls the processing of data that deals with living (or "natural") persons. This legislation is similar enough to FERPA and HIPAA regulations that American archivists can examine his paper with third party information in mind, but can also consider the ethical implications of information sharing that is illegal in countries outside of the United States.

Stillitoe's paper points out that racial information, political opinions, religious or cultural beliefs, union memberships and physical or mental health (including sexual orientation or sexual health) is all considered personal (and therefore private) information in the United Kingdom and can only be divulged with third party permission. This means a complete shift in the thought process of archivists of what is considered sensitive material. Stillitoe recommends that "where no breach of confidence is involved, the standard public records access period, presently 30 years, should be confirmed as the period before which any personal information will normally be made publically available, whether from public or private records" (Stillitoe, 2008). Because this legislation was not created with the intention of archives, Stillitoe argues, it is better to go along with it for now, and accept it as a way to protect the public from itself, and the archive from third party lawsuits due to material in government or corporate body collections that may collect information that is considered sensitive or private.

There is, of course, another body whose legal rights are examined by archivists and theorists, and that body is the governmental body, whose rights are often taken as having higher precedence than the rights of individual citizens. The legal ramifications of privacy when government bodies are taken into account are essential for archivists to examine because government bodies often have some measure of financial or legal control over archival material. Wallace Eberhard (2000) discusses the conflicting nature of access against the concept of 
national security, Gregor Trinkaus-Randall (2008) dissects the implications of the Patriot Act in archives, while Abiola Abioye (2010) examines the case of Nigeria and the implications of privacy and official records in the era of Freedom of Information. These papers examine the concept of privacy through a critical lens of government interaction, and suggest that privacy is not simply a legal requirement to protect the creator of archives, but also to protect the users from information, even in the age of freedom of information.

Eberhard begins the conversation with a historical overview of secrets in reference to national security, and how the United States has historically dealt with state secrets, even though the creation of the Freedom of Information Act which "included a specific exemption for national security information, it provided a mechanism for access to non-national security documents" (Eberhard, 2000). He goes further to dissect the nature of access, and how the people of the United States are more aware of accessibility than ever. This is problematic because of the interaction of government access and public access, and their intersections can often cause problems in information environments. He claims that "challenges could be formidable in a future war, and current problems abound in trying to maintain crypto-security for classified information" (Eberhard, 2000). The entire tone of Eberhard's document follows this notion: that the public is in the government's path by demanding some form of access to information.

This attitude is not shared by Trinkaus-Randall, who outlines how difficult finding, accessing, and retaining research information could be for users when faced with formidable opposition such as the Patriot Act. He points out that both privacy and confidentiality are "fundamental to the functioning of libraries and archives" (Trinkaus-Randall, 2008) but that the Patriot Act, as federal law (and thus above state laws that dictate privacy and confidentiality in libraries and archives) require librarians and archivists comply with subpoenas, searches, and requests for confidential information. He points out that the Patriot Act may make the first amendment as information professionals see it, including "the freedom to hear and the freedom to read" (Trinkaus-Randall, 2008) impossible, as the government now is capable of seizing this information for dissemination. This is only furthered by Elizabeth Shepherd's (2007) examination on the UK Freedom of Information (FOI) Act. The FOI was designed with the intention of opening records up for more public scrutiny, particularly governmental and organization records. Shepherd points out that "FOI seemed to have brought about improvements in both senior management awareness and in the provision of resources to implement records management programmes" (Shepherd, 2007) but that these improvements were mostly only seen in non-digital materials, and that digital records still presented a challenge to record keepers. Despite this, Shepherd's research concludes that FOI and the resulting freedom of access to government require more research to truly examine if "FOI has brought greater accountability and discover any specific positive benefits for users." (Shepherd, 2007). While FOI has not been implemented for long enough to distinguish any positive effects, it is a good contrast to the Patriot Act, where one seeks to retain privacy and the other seeks to relinquish it.

One may wonder how Nigeria, and the case that Abiola Abioye refers to, would be involved in this. Nigeria's laws, according to Abioye, seem to favor state secrets. Their recent democracy and previous dictatorships, "not satisfied with the restrictive provisions of the Official Secrets Act, Criminal Code Act and Public Services Rules [all codes, laws, and restrictions designed to prevent the dissemination of information and to restrict public access to records] the various military regimes also engaged various other decrees with sought to restrict access to and purveyance of information about government" (Abioye, 2010). Abioye suggests that it is the youth of Nigeria's democracy that makes the dissemination of information so 
difficult, which is even more interesting in relation to the United States when Abioye persists to remark that "one should expect that the dominant culture and belief systems in respect of public records and information both within government and society would be those that support restriction of access to such records and information" (Abioye, 2010). This basically states that the concept of access, particularly in relation to government records, or in relation to what the government classifies as private, is slowly absorbed into a cultural ideal. Nigeria's restriction of access has led to a culture that views lack of accessibility as the norm. Viewed from a Western perspective, and reflected against Eberhard's notions of privacy and public access as complicating government access, it is easy to see where the American public culture can transform into one of secrecy. The conversation with writers such as Trinkaus-Randall, who implores that libraries and archives develop strong policies to protect users and examine records for their necessity are crucial to promote the continual access even against a strong governmental policy of privacy for government records.

However, there is another side of restriction to archival accessibility: one that relies less on legal ramifications and more on ethical consideration of complicated issues. Often the lines between legalities and ethics are blurred, particularly where access is concerned, as copyright can be seen as an ethical issue as well as a legal one, particularly where the continual copying of materials is concerned, but ethical issues often have less emphasis on the case of law and a heavier emphasis on the people who are affected by open access to privileged material. This is often where the concept of privacy extends into the area of restriction. For the sake of this review, the definition of restriction differs from privacy in that where privacy is about the rights belonging to the creator of collections, restriction discusses the rights available to users.

In order to fully examine restriction and user rights, and where that intersects with privacy, the concept of archival ethics has to be examined and detailed in great length. The topic of archival ethics could be a paper on its own, but the intersection is a critical point for any discussion on the ethics of restriction. Karen Benedict begins this conversation by defining ethics and their relationship to archives, including a brief history of the archivist code of ethics, and an examination of the current code of ethics. She states that this code "enumerates major areas of archival responsibility, defining the accepted practices or behavior in each of them" (Benedict, 1989). She touches on privacy as "where profit from information gained or the revelation of information from restricted holdings is prohibited" (Benedict, 1989), which infers that ethically, archivists are obligated to not derive profit from restricted materials such as "case files from mental hospitals, orphanages, and other such institutions" (Benedict, 1989). Paul Gates Jr. (2000) both broadens and specifies this, claiming that any control that is not exerted by the creator of the material can be considered "intrusion" or "the intentional invasion of the solitude or seclusion of another in his or her private affairs or concerns through either physical or electronic means" (Gates, 2000) and that ethically, archivists and record keepers are ethically responsible from keeping intrusion to a minimum by users that seek profit - Gates specifies media intrusion, in his case studies, but this could be extended into any intrusion for which the ultimate goal is to gain profit from private information. Both of these papers seem to imply that if private papers are in fact accessed, it can be accessed with a guarantee that the use is private, and not public (that is to say that the user would only access these files with a specific goal of discovering a private detail that they would then not use for profit, whether that profit is monetary or academic in nature).

This conversation then expands into two distinct ethical questions. The first is the question of the ethics of restriction and access of oral materials. The creation of oral materials, or recorded material, is a relatively recent development in the history of archiving, and many of the 
ethical dilemmas that surround the creation, preservation, and access of oral materials are still in question. Bruce Breummer (1991) begins this conversation with an overview of the access issues that affect oral materials, which range from neglect to poor cataloguing methods. While he only very briefly touches on restricting material - mainly to suggest that restricted materials should be opened as quickly as possible, to enhance user access, he also makes the suggestion to "support the goal of adequate access to oral history collections by the oral history community" (Breummer, 1991) with the implication that this goal eliminate the pitfalls of restriction. Shirley Stephenson (1987) argues, however, that it is vital to protect oral history collections for legal and ethical reasons with strong policy and stronger contract drafting. While the legal ramifications are ceaseless and complicated, including joint copyright by both the interviewee and the interviewer, copyright law that has not completely caught up with technology, and other legal loopholes, the ethical ones are equally entrenching (Stephenson, 1987). Stephenson points out that "many interviews... have been known to elicit extremely personal information or highly derogatory remarks that students working on the project have shared" and that "students, transcribers, editors, and proofreaders alike should be cautioned that recorded information should always be respected and treated in a professional and confidential manner" (Stephenson, 1987). In essence, oral materials possess a higher risk of intrusion because these materials, unlike paper materials, are not so easily edited.

This issue is even more complex with the digital age and the possibility of internet access is introduced. Alex Byrne (2003) discusses the digital library as a "new digital paradigm" (Byrne, 2003) and discusses the possibility of access to digital materials, both digitized and digital born. Ideally, he states, that "access is available globally 24 hours a day without geographical limitation" and that of the restrictions imposed, most restrictions are linguistic and not privacy-oriented. However, he does examine the problem of the paywall and the rising cost of scholarly information. Digital content can be expensive to host and manage, and therefore restriction may be more due to lack of funds than due to a desire for privacy. This is relevant against the arguments made by Dejah T. Rubel (2007). Rubel outlines the copyright law regarding oral histories and presents it with the distinct situation of digitized, internet-accessible oral history as a focaliser. Oral histories are readily suited for the internet, Rubel argues, as sound exists mainly on digital platforms in modern oral histories and is easily transferred as files between repositories. However, Rubel also points out that "by not being physically present when the collection is accessed, regardless of the format, the archivist relinquishes both the ability to show the materials in context and ensure that professional standards are applied for their use" (Rubel, 2007) and that ethically this presents a problem in the use of materials, as any restrictions of use may not transfer over in a digital format, and permissions can be bypassed through use of software manipulation and technology. This is not simply a legal issue, but an ethical one, because it does not allow for archivists to gauge and supervise the use of oral histories and archival material, in the case that restricted material could be used for profit or intrusion.

In a related issue, tremendous ethical consideration that has become more apparent and more pressing, especially with the subject of audio and visual materials, is the ethical consideration of the collecting, storing, and use of cultural materials. While this subject has a number of iterations, such as the theft of materials from colonized (and now independent) nations, or the theft of artifacts from developing independent nations, the most pressing matter in the topic of ethical restriction of materials comes from the use of indigenous cultural artifacts and knowledge in repositories, not just in the United States, but around the world. Jane Anderson (n.d) presents an Australian perspective, but also opens a conversation regarding the use of 
indigenous knowledge and intellectual property that can be applied to many different situations. Anderson begins by pointing out the difficulties in keeping indigenous materials, including that institutions often control access because "they are, in most cases, the copyright owners," (Anderson) which means that members of the indigenous group, even relatives, have little say in access, for or against. Anderson goes on to discuss how indigenous groups are challenging this, as institutions should not own copyright to material that belongs in private space. Indigenous communities are solving the problem of access with their own institutions, ones that "develop quite a specific community intellectual property protocol...[that] would not emanate from larger organisations" (Anderson) which allows intellectual property that is presented to indigenous institutions to follow indigenous cultural practices with the dissemination of knowledge, and preventing unwanted intrusion. These policies "raise(s) the bar in relation to how institutions do deal with Indigenous Knowledge Centres" (Anderson) because it empowers the community to make decisions on their intellectual and cultural property without needing to refer to colonizers for guides to how to best restrict material.

Roy and Alonzo (2003) bring the conversation over to the United States by introducing and discussing the concept of a tribal archive, which, like tribal libraries, are designed to document and hold tribal perspectives. They begin with an analysis of how tribal archives function, how they are governed by a tribal council and their relationship to laws such as NAPGRA, which, "in order to repatriate objects, tribes must have documentary proof of what is theirs" (Roy and Alonzo, 2003) and how they can serve the community with historical proof of "land and water rights, disputes in the local industry or economy" (Roy and Alonzo, 2003). They address several concerns, focus on examination of privacy and restriction of access and the act of digitization. "Technological applications in handling cultural materials causes additional hesitancy when non-Native staff are involved in handling cultural material and in displaying them both to the community and beyond" (Roy and Alonzo, 2003) they write, prompting a swift conversation on the importance of training Native archivists to handle cultural material which may be restricted for cultural reasons. They go on to discuss the reasons that tribal archives may be restricted, such as to prevent looting, or because some material can only be viewed by a particular cultural group within the indigenous community itself, such as men or elders. These issues can be exacerbated by digitization, where control can quickly be lost because of the ease of digital access on the internet. Despite the benefits, such as allowing a larger breadth of the community to identify images, places, or cultural materials, and allowing the community to assist in cataloging, Roy and Alonzo wonder how much intrusion will occur in a digital space. However, they maintain that "tribal archivists will need to determine who will sanction work with cultural materials" (Roy and Alonzo, 2003) and that in the end, it will be a case-by-case scenario, with the conversation belonging to archivists in the community and tribal elders, prominently leaving out larger institutions, as is noted by Anderson. The consensus seems to be that restriction must be decided by communities to protect themselves, not by larger institutions.

The general examination of privacy and restriction, then, shows a number of different issues that archives must contend with in order to be conversant in how to best protect creator privacy and restrict user access. Copyright, sensitive material, government agencies and cultural competency must all be taken into account when creating accessible collections, and in deciding when to restrict material. These considerations must be both legal and ethical in nature, but I would argue must also take the user into account. While the desire to make everything accessible is strong, it is simply not feasible when laws and ethics are both taken into account, but the repository's need to serve the public must also be examined. However, there are solutions: 
stronger policies that clearly outline copyright and which material must be restricted, strong accession policies that determine if restricted material will even be accepted by repositories, and, in the case of sensitive cultural material, strong community input as to the state of archival material. What remains are studies that show the impact of community involvement in quantitative ways, instead of simply as a report that it is happening. As this material becomes more and more digitized, this foundation must be in place to protect against intrusion and against the release of private or restricted information.

\section{Reference List}

Abioye, A. (2010). Confidentiality and the Protection of Official Records in the Freedom of Information Era: The Nigeria Case. Archives and Information Science, 20(1), 29-39.

Anderson, J. (n.d.) Indigenous Knowledge, Intellectual Property, Libraries and Archives: Crises of Access, Control and Future Utility. Australian Indigenous Knowledges and Libraries.

Benedict, K. (1989). Archival Ethics. In J. G. Bradsher (Ed.), Managing Archives and Archival Institutions. Chicago: University of Chicago Press.

Breummer, B. (1991). Access to Oral History: A National Agenda. The American Archivist, 54(4), 494-501.

Byrne, A. (2003). Digital libraries: barriers or gateways to scholarly information? The Electronic Library, 21(5), 414-421.

Carson, B. (2007). The Law of Libraries and Archives. Lahnam, MD: The Scarecrow Press, Inc.

Chmara, T. (2009). Privacy and Confidentiality Issues: A Guide for Libraries and their Lawyers. Chicago: American Library Association.

Eberhard, W. (2000). The Threat from Within: Balancing Access and National Security. In C. Davis \& S. Splichal (Eds.), Access Denied (pp. 195-222). Iowa: Iowa State Press.

Gates, P. (2000). Privacy and Access: The Inevitable Collision of Competing Values. In C. Davis \& S. Splichal (Eds.), Access Denied: Freedom of Information in the Information Age. Iowa: Iowa State University Press.

Jaak, V., \& Birgit, K. (2007). Restrictions on Access to Archives and Records in Europe: A History and the Current Situation. Journal of the Society of Archivists, 28(2).

Kurtz, M. (2004). Managing Archival \& Manuscript Respositories.

Pyatt, T. (2008). Balancing Issues of Privacy and Confidentiality in College and University Archives. In C. Prom \& H. Swain (Eds.), College and University Archives. Chicago: Society for American Archivists. 
Roy, L., \& Alonzo, D. (2003). Perspectives on Tribal Libraries. The Electronic Library, 21(5), 422-427.

Rubel, D. (2007). Accessing Their Voice from Anywhere: Analysis of the Legal Issues Surrounding Online Use of Oral Histories. Arch Issues, 31(2), 171-187.

Shepherd, E. (2007). Freedom of Information and Records Management in the UK: What has been the impact? Journal of the Society of Archivists, 28(2), 125-138.

Sniffin-Marinoff, M. (2007). Privacy and Confidentiality Perspectives: Archivists and Archival Records by Menzi L. Behrnd-Klot, Peter J. Wosh. The American Archivist, 70(1).

Stephenson, S. (1987). Protect Your Collection: Oral History and Copyright. The Public Historian, 9(4), 20-33.

Stillitoe, P. (1998). Privacy in a Public Place: Managing Public Access to Private information Controlled by Archives Services. Journal of the Society of Archivists, 19(2).

Trinkaus-Randall, G. (2008). The USA PATRIOT Act: Archival Implications. Journal of Archival Organization.

Wiener, J., \& Gilliland, A. (2011). Balancing Between Two Goods: Health Insurance Portability and Accountability Act and Ethical Compliancy considerations for privacy-sensitive materials in health sciences archival and historical special collections. Journal Medical Library Association, 99(1). 